\title{
Similar risk of malignancy with insulin glargine and neutral protamine Hagedorn (NPH) insulin in patients with type 2 diabetes: findings from a 5 year randomised, open-label study
}

\author{
J. Rosenstock • V. Fonseca - J. B. McGill • M. Riddle • \\ J. P. Hallé • I. Hramiak • P. Johnston • M. Davis
}

Received: 26 June 2009 /Accepted: 29 June 2009 /Published online: 16 July 2009

(C) The Author(s) 2009. This article is published with open access at Springerlink.com

Keywords Cancer · Insulin analogues · Insulin glargine · Insulin therapy · Malignancy $\cdot \mathrm{NPH}$ insulin $\cdot$ Type 2 diabetes

\section{Abbreviations \\ MedDRA Medical Dictionary for Regulatory Activities NPH Neutral protamine Hagedorn}

To the Editor: We have reported a randomised, long-term safety study comparing the effects of using the insulin analogue glargine (A21Gly,B31Arg,B32Arg human insulin) versus human neutral protamine Hagedorn (NPH) insulin for 5 years in the management of type 2 diabetes [1]. The study, in which 1017 patients were randomised and treated, was

\footnotetext{
J. Rosenstock

University of Texas Southwestern Medical School,

Dallas, TX, USA

J. Rosenstock $(\bowtie)$

Dallas Diabetes and Endocrine Center at Medical City,

7777 Forest Lane C-685,

Dallas, TX 75230, USA

e-mail: juliorosenstock@dallasdiabetes.com

V. Fonseca

Tulane University Medical Center,

New Orleans, LA, USA

\section{J. B. McGill}

Washington University School of Medicine,

St Louis, MO, USA

M. Riddle

Oregon Health and Science University,
}

Portland, OR, USA designed to assess ocular complications of diabetes: there was no excess of such effects with insulin glargine compared with NPH insulin treatment and there was a similar slow progression of diabetic retinopathy with both types of insulin. Because of recent concerns about postulated neoplastic effects of insulins [2-5], we report here additional information from our study that bears on this question.

In total, the mean cumulative exposure in our study was more than 4 years $(1,524$ days in the insulin glargine group and 1,522 days in the NPH insulin group), with more than $70 \%$ of patients exposed to more than 4 years of treatment ( $76 \%$ and $71 \%$, respectively) (Table 1 ).

The baseline demographics and diabetes status were similar between the two treatment groups (insulin glargine vs NPH insulin): diabetes duration (10.7 vs 10.8 years),

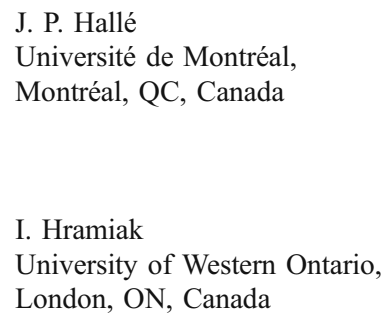

I. Hramiak

University of Western Ontario,

London, ON, Canada

\author{
P. Johnston \\ sanofi-aventis, \\ Bridgewater, NJ, USA
}

M. Davis

University of Wisconsin School of Medicine and Public Health, Madison, WI, USA 
Table 1 Summary of extent of exposure (safety population)

Data are mean \pm SD unless otherwise stated

\begin{tabular}{lll}
\hline Variable & Insulin glargine $(n=514)$ & NPH insulin $(n=503)$ \\
\hline $\begin{array}{ll}\text { Cumulative exposure (patient-years) } \\
\text { Extent of exposure (days) }\end{array}$ & 2144.0 & 2095.8 \\
Mean & $1523.55 \pm 571.77$ & $1521.82 \pm 562.14$ \\
Median & 1821.50 & 1823.00 \\
\hline
\end{tabular}

BMI (34.5 vs $\left.34.1 \mathrm{~kg} / \mathrm{m}^{2}\right)$, oral hypoglycaemic agent duration (9.0 vs 8.9 years), prior insulin use (67\% vs $70 \%), \mathrm{HbA}_{1 \mathrm{c}}(8.4 \%$ vs $8.3 \%)$ and fasting plasma glucose (10.5 vs $10.0 \mathrm{mmol} / \mathrm{l})$.

Although the study was not designed to investigate the frequency of tumour development, the long duration of the trial enables a comparative assessment of the occurrence of benign or malignant tumours with insulin glargine and NPH insulin during more than 4 years of exposure, captured as adverse events in the course of routine safety monitoring. The number of patients with treatment-emergent adverse events (defined as events that first occurred or worsened after randomisation) of neoplasm, summarised by System Organ Class and High-level Group Term levels using the standard Medical Dictionary for Regulatory Activities (MedDRA) coding dictionary (version 10.0; Maintenance and Support Services Organization, Chantilly, VA, USA) [6], are shown in Table 2. Benign and malignant tumours reported by the investigators, along with those of unspecified pathology, are included. A more detailed listing of MedDRA-coded neoplasms is available [7].

The overall number of patients with neoplasms (using the standard MedDRA coding dictionary) occurring during the trial was similar in the two treatment groups: 57 patients $(11.1 \%)$ in the insulin glargine group vs 62 patients $(12.3 \%)$ in the NPH insulin group, with an RR for insulin glargine of 0.90 (95\% CI 0.64-1.26). In addition, when only the number of patients with malignant neoplasms reported as serious

Table 2 Patients with neoplasms reported as treatment-emergent adverse events

\begin{tabular}{|c|c|c|}
\hline All neoplasms ${ }^{\mathbf{a}}$ & Insulin glargine $(n=514)$ & NPH insulin $(n=503)$ \\
\hline Any event & $57(11.1)$ & $62(12.3)$ \\
\hline Breast neoplasms, malignant & $3(0.6)$ & $5(1.0)$ \\
\hline Cutaneous neoplasms, benign & $13(2.5)$ & $12(2.4)$ \\
\hline Endocrine neoplasms, malignant & $5(1.0)$ & $7(1.4)$ \\
\hline Gastrointestinal neoplasms, malignant & $6(1.2)$ & $9(1.8)$ \\
\hline Haematopoietic neoplasms & $1(0.2)$ & 0 \\
\hline Hepatobiliary neoplasms, malignant & 0 & $1(0.2)$ \\
\hline Lymphomas, non-Hodgkin's B cell & 0 & $1(0.2)$ \\
\hline Metastases, unspecified neoplasm & 0 & $1(0.2)$ \\
\hline Miscellaneous and site unspecified neoplasms, malignant & $1(0.2)$ & $3(0.6)$ \\
\hline Nervous system neoplasms, benign & $1(0.2)$ & $2(0.4)$ \\
\hline Ocular neoplasms, benign or malignant & $3(0.6)$ & $2(0.4)$ \\
\hline Plasma cell neoplasms, benign or malignant & $1(0.2)$ & 0 \\
\hline Renal and urinary tract neoplasms, malignant & $2(0.4)$ & $1(0.2)$ \\
\hline Reproductive neoplasms female, benign & $2(0.4)$ & $1(0.2)$ \\
\hline Reproductive neoplasms female, malignant & $2(0.4)$ & $4(0.8)$ \\
\hline Reproductive neoplasms male, malignant & $2(0.4)$ & $3(0.6)$ \\
\hline Respiratory and mediastinal neoplasms, malignant & $6(1.2)$ & $2(0.4)$ \\
\hline Skin neoplasms, malignant & $11(2.1)$ & $9(1.8)$ \\
\hline Soft tissue neoplasms, benign & $3(0.6)$ & $4(0.8)$ \\
\hline Soft tissue sarcomas, benign or malignant & 0 & $1(0.2)$ \\
\hline
\end{tabular}

Data are $n(\%)$, in alphabetical order

All patients with neoplasm-coded adverse events (whether considered serious or non-serious) as reported by the investigator are included. Patients may have had more than one adverse event

${ }^{a}$ Includes MedDRA System Organ Class 'Neoplasm benign, malignant and unspecified (including cysts and polyps)' (version 10.0) [6] 
treatment-emergent events was captured, the rate was also similar in both treatment groups: 20 patients $(3.9 \%)$ with 23 events in the insulin glargine group vs 31 patients $(6.2 \%)$ with 32 events in the NPH insulin group, with an RR for insulin glargine of 0.63 (95\% CI 0.36-1.09).

The number of patients with malignant breast tumours reported was also similar between the two treatment groups: three patients in the insulin glargine group (all reported as serious) compared with five patients (four reported as serious) in the NPH insulin group.

The RR estimate of all malignant breast tumour cases, including non-serious cases (three in the insulin glargine group vs five in the NPH insulin group) numerically favours insulin glargine (RR $0.59,95 \%$ CI $0.14-2.44$ ). Although the 95\% CI includes 2, it must be noted that due to the small numbers of patients and the small number of cases, there was only a $22 \%$ power to reject a doubling in the risk (RR 2.0) of developing this tumour, should the true risks be equal.

Considering all neoplasms (RR 0.9) and all malignant neoplasms (RR 0.63), the results numerically favour insulin glargine with 95\% upper CI limits of 1.26 and 1.09 , respectively, indicating at most a $26 \%$ and $9 \%$ increase in risk.

In summary, this study is the longest controlled treatment comparison of insulin glargine versus $\mathrm{NPH}$ insulin in patients with type 2 diabetes mellitus. No new safety issues emerged for either insulin studied based on the data from this 5 year trial. Additional data reported here also confirm that there was no evidence of any difference in the rate of benign or malignant tumour development with insulin glargine compared with NPH insulin.

Duality of interest J. Rosenstock has received grants for research from and/or has been a consultant to Amylin, Boehringer-Ingelheim, Bristol-Myers Squibb, Centocor, Eli Lilly, Emisphere, GlaxoSmithKline, Johnson \& Johnson, MannKind, Merck, Novartis, Novo Nordisk, Pfizer, Roche, Sankyo, sanofi-aventis and Takeda. V. Fonseca has received research support (to Tulane University) with grants from GlaxoSmithKline, Novartis, Novo Nordisk, Takeda, Astra-Zeneca, Pfizer, sanofi-aventis, Eli Lilly, Daiichi-Sankyo, Novartis, the National Institutes of Health (NIH) and the American Diabetes Association (ADA), and honoraria for consulting and lectures from GlaxoSmithKline, Novartis, Takeda, Pfizer, sanofiaventis and Eli Lilly. J. McGill has received grant support (to Washington University) from sanofi-aventis, Pfizer, Eli Lilly, Novo Nordisk, Novartis, GlaxoSmithKline, Elixir, Tolerx, Biodel, MannKind, Takeda; served on advisory boards and speakers' bureaus for sanofi-aventis and Novo Nordisk, and on speakers' bureaus for Eli Lilly, Merck, Novartis, Daiichi-Sankyo, Forest and GlaxoSmithKline; and has been a consultant/advisor for Merck, Novo Nordisk, Elixir, MannKind and Amgen. I. Hramiak has received research grant support from Pfizer, sanofi-aventis, Novo Nordisk and Eli Lilly, and has served on advisory boards for GlaxoSmithKline, Novo Nordisk, sanofi-aventis and Merck. J.-P. Hallé has received grants for research from and/or has been a consultant and/or on the speaker bureau of Bristol-Myers Squibb, ConjuChem, Bellus Health, Eli Lilly, GlaxoSmithKline, Merck Frosst, Novartis, Novo Nordisk, Pfizer, Roche, sanofi-aventis and Takeda. M. Riddle has received grants for research and/or honoraria for consulting or lectures from Amylin, Lilly, the AmylinLilly Alliance, Novo Nordisk, Pfizer, sanofi-aventis and Valeritas. P. Johnston is an employee of, and holds stock options from sanofiaventis. M. Davis has received research support from sanofi-aventis.

Open Access This article is distributed under the terms of the Creative Commons Attribution Noncommercial License which permits any noncommercial use, distribution, and reproduction in any medium, provided the original author(s) and source are credited.

\section{References}

1. Rosenstock J, Fonseca V, McGill JB et al (2009) Similar progression of diabetic retinopathy with insulin glargine and neutral protamine Hagedorn (NPH) insulin in patients with type 2 diabetes: a long-term, randomised, open-label study. Diabetologia. doi:10.1007/s00125-009-1415-7

2. Currie CJ, Poole CD, Gale EAM (2009) The influence of glucoselowering therapies on cancer risk in type 2 diabetes. Diabetologia. doi:10.1007/s00125-009-1440-6

3. Hemkens LG, Grouven U, Bender R et al (2009) Risk of malignancies in patients with diabetes treated with human insulin or insulin analogues: a cohort study. Diabetologia. doi:10.1007/ s00125-009-1418-4

4. Colhoun HM, SDRN Epidemiology Group (2009) Use of insulin glargine and cancer incidence in Scotland: a study from the Scottish Diabetes Research Network Epidemiology Group. Diabetologia. doi:10.1007/s00125-009-1453-1

5. Jonasson JM, Ljung R, Talbäck M, Haglund B, Gudbjörnsdòttir S, Steineck G (2009) Insulin glargine use and short-term incidence of malignancies - a population-based follow-up study in Sweden. doi:10.1007/s00125-009-1444-2

6. MedDRA - the Medical Dictionary for Regulatory Activities (2009) Available from www.meddramsso.com/MSSOWeb/index. $\mathrm{htm}$, accessed 25 June 2009

7. ClinicalStudyResults.org (2009) Available from www.clinicalstudy results.org/, accessed 25 June 2009 